\title{
Review of: "Interventions to increase personal protective behaviours to limit the spread of respiratory viruses: A rapid evidence review and meta-analysis"
}

\author{
Haywantee Ramkissoon ${ }^{1}$
}

1 University of Derby

Potential competing interests: The author(s) declared that no potential competing interests exist.

This paper is timely and has now been revised to shed further lights on some important points as follows. Authors recognise that their study was limited to a few databases, however reflected the study dealt with the main databases. This was due to the need to synthesise evidence quickly during the current COVID-19 pandemic. They have now highlighted this as a limitation of the study.

This paper is likely to attract good readership as it makes an important contribution to the COVID-19 literature. 